Article

\title{
Aid Targeting to Fragile and Conflict-Affected States and Implications for Aid Effectiveness
}

\author{
David Carment * and Yiagadeesen Samy \\ Norman Paterson School of International Affairs, Carleton University, Ottawa, ON K1S 5B6, Canada; \\ E-Mails: david.carment@carleton.ca (D.C.), yiagadeesen.samy@carleton.ca (Y.S.) \\ * Corresponding author
}

Submitted: 30 November 2018 | Accepted: 22 January 2019 | Published: 5 June 2019

\begin{abstract}
While significant amounts of foreign aid have been allocated to the group of so-called fragile and conflict-affected states in recent years, it is not clear whether that aid is targeted to where it is most needed. This article extends recent work by Carment and Samy (2017, in press), and focuses on aid targeting in fragile states by using the Country Indicators for Foreign Policy fragility index together with sectoral aid flows from the OECD Creditor Reporting System. Specifically, it considers six country-cases from a three-fold typology of states and evaluates the performance of these countries in terms of their fragility relative to the types of aid that they have received. The article argues that aid is poorly targeted in fragile states and by considering the sectoral allocation of aid it also contributes indirectly to the related issue of aid effectiveness.
\end{abstract}

\section{Keywords}

aid effectiveness; aid targeting; conflict-affected states; foreign aid; fragile states

\section{Issue}

This article is part of the issue "Aid Impact and Effectiveness", edited by Rachel M. Gisselquist and Finn Tarp (UNU-WIDER, Finland).

(C) 2019 by UNU-WIDER; licensee Cogitatio (Lisbon, Portugal). This article is licensed under a Creative Commons Attribution 4.0 International License (CC BY).

\section{Introduction}

Fragile and conflict-affected states (FCAS) have attracted a significant amount of donor attention and resources in recent years. ${ }^{1}$ According to the latest States of Fragility report by the OECD (2018), donors spent US\$ 68 billion or more than $65 \%$ of their earmarked funding in 58 fragile contexts in 2016, and hence more than in other developing countries. Given that poverty will become increasingly concentrated in fragile states in the next decade, and that progress in these countries has been slow historically, it is likely that aid flows in FCAS will continue their steady increase. We also know that the amounts spent in these fragile countries are not evenly spent, giving rise to the phenomenon of aid darlings and aid orphans. A few papers have used large- $\mathrm{N}$ analysis to examine aid allocation and aid effectiveness in fragile countries. For example, McGillivray (2006) and McGillivray and Feeny (2008) examine aid allocation, and aid and growth, in fragile states respectively. They find that fragile countries face difficulties in absorbing the amounts of aid they receive when compared to other countries and that growth would have been lower in the absence of aid. Carment, Prest and Samy (2008) find that aid is allocated to fragile states on the basis of their capacity and authority structures but not according to legitimacy, which could be problematic if countries remain trapped or face challenges in overcoming fragility as a result of lack of legitimacy. However, these empirical studies consider fragile states as a group and do not fully exploit the different ways in which countries are fragile. Indeed, few are the studies that focus on the policy implications of fragility persistence by considering specific country-cases. An early study by Chauvet and Collier (2008) found that the

\footnotetext{
${ }^{1}$ We use the term fragile states, fragile contexts, fragile countries and FCAS interchangeably in this article.
} 
average duration of a failing state is a prolonged period of five decades because external financing for resource exports and aid tend to embolden and support rent seeking elites and retard reforms. Andrimihaja and his colleagues in their 2011 World Bank study cited a combination of weak property rights enforcement, corruption, insecurity and violence, which conspire to create a low growth equilibrium (Andrimihaja, Cinyabuguma, \& Devarajan, 2011). But what neither of these studies clarify is how these factors work together to generate fragility persistence.

To address this deficiency in theorising, in recent years we have begun to see the emergence of a multidimensional approach to the identification and classification of fragile states (Carment, Prest, \& Samy, 2009; Call, 2011; Gravingholt, Ziaja, \& Kreibaum, 2015; OECD, 2015). In this article, we draw from the Country Indicators for Foreign Policy (CIFP) fragile states framework proposed by Carment et al. (2009) to conduct our analysis. According to the CIFP framework, for a state to function properly it needs to exhibit three fundamental properties: authority (A), legitimacy (L) and capacity (C). Fragility, again according to the CIFP framework, refers to the extent to which the actual characteristics of a state differ from their ideal situation. Viewed in this way, all states are to some extent fragile and weaknesses in one or more of these three fundamental properties will have a negative impact on their fragility. The CIFP framework thus includes an overall index of fragility and these three different characteristics of stateness, also known as the ALC framework. Authority refers to the legislative power of the state and its ability to control its territory, to provide core public goods, stability and security to its people. Legitimacy refers to how much a particular government commands loyalty to the governing regime and how much domestic support it generates for its legislation and policy. Capacity refers to the ability of the state to mobilize and employ resources towards productive ends. ${ }^{2}$ To obtain composite scores for authority (A), legitimacy (L) and capacity (C), various indicators are converted to a nine-point score based on the performance of a country relative to a global sample of countries. A higher score indicates that a country is performing poorly relative to other countries. Whether a state is strong or vulnerable is relative, and while certain states are strong or resilient by certain measures, they are weak by others. As recently pointed out by the Fund for Peace, fragility affects even the world's richest and developed countries, as both the United States and the United Kingdom are facing unprecedented internal political divisions, with the main difference, however, being that they have stronger capacity and resilience than more fragile countries (see Messner, 2018).

This article extends recent work by Carment and Samy (2017, in press) to consider aid targeting in fragile states. Its core argument is that aid is poorly targeted in fragile states; in particular, current aid allocations in the chosen country-cases do not pay sufficient attention to issues of authority and legitimacy that are both important for understanding why countries are fragile. Since Burnside and Dollar (2000), much attention has been devoted to the allocation of aid to countries with good policies. However, as pointed out by Hansen and Tarp (2000), the Burnside-Dollar policy selectivity result is sensitive to data and model specification, which makes the selectivity argument less robust. Furthermore, despite the evidence of non-linearities in the aid-growth relationship, it may well be the case that those countries that do not have good policies in place are the ones that need aid the most (Hansen \& Tarp, 2000). We are well aware of this dilemma in the case of fragile states, which by definition are characterized by poor policy environments. Our argument is not that aid should not be allocated to countries that face authority and legitimacy challenges. Instead, we argue that aid could be better targeted to these weaknesses in order to improve its effectiveness. The remainder of the article proceeds as follows. In the next section, we present a typology of states using the fragile states framework (Carment et al., 2009) discussed above. Section 3 summarizes the evolution of fragility using both quantitative analysis and the examination of six country-cases drawn from the typology discussed in Section 2. Section 4 analyses how aid is spent in the six identified country-cases using the OECD Creditor Reporting System (CRS) database. Section 5 concludes with the policy implications of our analysis.

\section{A Typology of States}

Just like Tolstoy's unhappy family, each fragile state is unique in its own way. However, we argue that we can categorize countries according to three types of states when one considers their performance over time: states that are stuck in a fragility trap, states that move in and out of fragility, and states that have exited fragility for a significant period of time. To be sure, these states are not identical in every aspect and neither are they fragile for the same reasons. However, their trajectories have followed particular patterns that allow them to be classified under one of these three types. As fragility rankings such as those from Fund for Peace and CIFP have shown, some countries have remained among the worst performers over time, with no sign of improvement. However, there are others who were once fragile and that have been able to build resilience and are no longer classified among current lists of fragile states. These are countries that we characterize as having exited fragility. There is also another category of in-between countries that have moved in and out of fragility, that is, where improvements in their situations did not last very long.

In order to identify countries for each type (trapped, in and out, and exited), we use the CIFP fragility index discussed earlier. The advantage of this index when com-

\footnotetext{
2 In addition to information about authority, legitimacy and capacity, countries are also scored according to various clusters that include governance, economics, security and crime, human development, demography, the environment, and gender as a cross-cutting theme.
} 
pared to others is that it is available over a few decades going back to $1980 .^{3}$ Given the persistence of fragility, this allows us to observe movements over an extended period of time that may be less visible with shorter time series such as the Fragile States Index of the Fund for Peace that is available since 2005 only. Countries that are trapped in fragility are those that are ranked among the top 20 fragile countries for more than half of the period from 1980 to 2015, and whose long-term trajectory according to fragility scores did not improve. This means that we consider both the ranking and fragility scores in order to avoid the possibility that the rank of countries could be negatively affected if other countries are doing better, even as the former are also improving. Trapped countries include the likes of Afghanistan, Chad, the Democratic Republic of the Congo, Pakistan, Somalia and Yemen.

Countries that moved in and out of fragility are those that were only able to exit the top 40 fragile countries for a short period of time and whose fragility scores were relatively flat over the long-term. While the choice of the top 40 might appear arbitrary, it is within the range of contexts identified as fragile-the OECD (2018) currently identifies 58 such situations-and if anything, imposed a more constraining condition on those countries that were deemed to have exited, albeit temporarily. In this group, one can find countries such as Cameroon, Laos, Mali, Rwanda and Senegal. Some of these countries are currently classified as fragile (OECD, 2018) but our analysis using CIFP's data indicates that they have been in and out of fragility. A third type of country consists of those that have exited fragility. These are countries that were among the most fragile countries in earlier years and exited the top 40 rankings for a period of ten years or more. Countries in this category display improvement in their fragility scores over the full period and include the likes of Algeria, Bangladesh, Guatemala and Mozambique. Although there is always a possibility that some of these countries might go back into fragility, and that some of them are still classified as fragile (OECD, 2018), the CIFP data indicates that they have been able to exit the top 40 rankings.

Classifications and typologies are challenging. Other than the more obvious cases that we consider trapped, different indices tend to rank and thus categorize countries differently and we are aware that our categorization of states as being in and out of fragility, or exited, may be disputed. However, for the purposes of this article, we are interested in categorizing so that we can then trace the evolution of these states over time using the ALC framework, which we address in the next section, and also to examine the allocation of aid to them.

\section{Evolution of States Using the ALC Framework}

\subsection{Trapped, In and Out, and Exit}

Why do countries end up being trapped, moving in and out of fragility, or exiting fragility altogether? The existing empirical literature on this issue remains fairly nascent. In their UNU-WIDER Research Working Paper, Carment and Samy (2017) find that there is strong evidence that capability and legitimacy traps are significant correlates of countries trapped in fragility, which when mapped onto the ALC framework indicate that authority and legitimacy are significant. ${ }^{4}$ They also find evidence of a conflict trap (that is, authority challenges) as a contributing factor and no evidence for the poverty trap when country fixed effects are taken into account. Overall, countries are trapped for reasons that are more related to authority and legitimacy, instead of capacity. Hence, their analysis, even if based on a small sample of ten countries using data collected for the period 1980-2015, and drawing from the CIFP ALC framework, indicates that focusing on capacity alone will not allow countries to escape the fragility trap when there are insufficient improvements to authority and legitimacy.

In an extension of this analysis to "in and out" states, Carment and Samy (in press) find that the conflict trap is important for that particular group. While the governments of countries in that category became more capable in some periods, their fragility scores only improved temporarily as a result of failure to exercise control over people and territories. On the other hand, the poverty and legitimacy traps are not as significant for them. Linking back to the ALC construct, authority seems to be the most important driver that prevented them from building resilience and stability more permanently. Finally, those countries that were able to exit fragility avoided the recurrence of large scale conflict (overcoming the conflict trap is significant in their case) but this was possible when they succeeded in building legitimacy as well. So, overall, the evidence indicates that authority and legitimacy are important drivers of fragility, with capacity playing a smaller role.

\subsection{Country-Cases ${ }^{5}$}

Building on these observations from the various types of fragile states identified above, we now turn our attention to six country-cases (two from each type) and how they have evolved, or not, over time, once again linking their evolution to the ALC framework. We should note that the selected cases are exemplars or typical countries

\footnotetext{
${ }^{3}$ Although the entire CIFP dataset is not made public, the methodology is fully transparent (see Country Indicators for Foreign Policy, n.d.). Data for the most recent year is publicly available each time the dataset is updated.

${ }^{4}$ Capability traps (Pritchett \& de Weijer, 2010, and Pritchett, Woolcock, \& Andrews, 2010) prevent fragile states from implementing basic functions such as service provision, the maintainance of law and order, and security. These factors are more in line with how authority is defined in the CIFP framework. In the case of legitimacy traps, they refer to countries that suffer from weak legitimacy due to high inequalities and authoritarian management (Takeuchi, Murotani, \& Tsunekawa, 2011).

5 For an extensive discussion of these cases, please see Carment and Samy (in press). Here we focus mostly on how fragility has evolved with respect to the ALC framework across these different cases.
} 
found under each type (trapped, in and out, and exited). We selected two under each category because we want to show that while these countries can be classified as belonging to specific types, they can be fragile for different reasons. There is no reason, for example, to expect Pakistan and Yemen to be fragile for similar reasons, and yet both are classified as countries trapped in fragility. In choosing our cases, we also wanted to make sure that they were in different regions of the world, as opposed to all, if not most, coming from the same region.

Let us therefore first consider Pakistan and Yemen as our two trapped states. Both are middle-income countries and are thus not among the poorest fragile countries. Their trajectories are different, with Yemen a collapsed state in the midst of a horrific civil war and Pakistan still deeply fragile but improving economically. Since unification in 1990, Yemen's fragility ranking has deteriorated, compared to fluctuating but moderate levels of fragility in the 1980s. Although there was a brief period of stability from 1995 to 1998, Yemen has been among the top 10 most fragile countries since 2001 according to CIFP's fragility index; following the outbreak of civil war and Saudi intervention in 2015, it was ranked 4th. 85,000 children under five are estimated to have died from extreme hunger or disease since the beginning of the civil war according to a recent report by Save the Children (2018). Authority, which has been very volatile as a result of conflict and terrorist events, and legitimacy, resulting from lack of support for Saleh's regime leading to his removal and the takeover of the government by the Houthis in 2015, have been the most important drivers of fragility in the case of Yemen.

Pakistan's average fragility rank was around 15 according to CIFP's fragility index, and it has remained in the top 20 most fragile states for most years over the 1980 to 2015 period. Both its authority and legitimacy scores have deteriorated in the last 20 years while capacity has remained stable. The country's inability to control internal conflict and the highly unequal nature of its society has meant that civilian and military governments have not been able to build legitimacy while developmental aid has reinforced a centralized authority structure, regardless of its legitimacy.

The fragility trap for Pakistan and Yemen are both related to problems of legitimacy that further undermine their authority structures, thus allowing for a negative interaction between legitimacy and authority. In general terms, strengthening authority structures without appropriate resource distribution goes hand in hand with declining legitimacy. Capacity is skewed to maintaining control over the distribution of resources and rents in favour of entrenched and unelected elites. Fissures based on ethnic cleavages, elite capture and rent seeking behaviour are met with coercive measures to maintain stability but come at the costs of further declines in legitimacy.

In examining the importance of a legitimacy feedback loop for Yemen, we see that deposed head of state
Saleh's leadership ideology had essentially been one of regime survival, as the system of governance under his rule was a savvy mixture of Islamic, conservative, and liberal economic policies (Carment \& Samy, 2017). Furthermore, his legitimacy stemmed primarily from his regime's ability to maintain stability and to provide rewards to his clients. Much of that stability stemmed from the aid Yemen received in support of its contribution to the Global War on Terror (Carment \& Samy, in press). Thus Yemen's fragility trap is a function of mutually reinforcing structural constraints. Saleh carefully constructed a patronage system that provided benefits to a select few clients (Clark, 2010). But that narrow support base also constrained his ability to improve the country's economy, for example through structural adjustment, and improved social services. As long as resources were available, such as rents from oil revenues, development assistance and military aid, the regime was secure and did not need to reform though the country itself remained deeply fragile. When those narrowly distributed benefits began to diminish, and as oil output declined, so too did Saleh's hold on power. Ultimately, his concentration of personal power and the neglect of the periphery left the field open to new challengers, such as disaffected southerners, Islamist groups, and the northern Houthi movement. Yemen's legitimacy feedback loop was lethal because Saleh's regime survival was tied to a declining rent economy leading to reduced capacity and control over territory and ultimately collapse.

Like Yemen, Pakistan's fragility challenges appear to be linked to problems of legitimacy which further undermine its authority structures. But here the legtimacy feedback loop is pernicious and so far non-lethal. Systemic social fissures, which pit ethnic and sectarian groups against each other, form the unsteady foundation upon which Pakistan's political institutions are built (Carment \& Samy, in press). Inequality between ethnic groups, in particular, has highlighted poor legitimacy as various calls for self-government by provincial regions seeking autonomous control over their resources clearly demonstrate a loss of confidence in the capacity of Pakistan's regimes to act in their interests. In addition, continued elite capture of power and resources has contributed to a depreciation in the quality of Pakistan's institutions. The result is a governance system that explicitly favours networks of unelected ruling elites, and a public with little trust for ruling regimes.

The negative reinforcement of Pakistan's authority structures is achieved through an institutional system, political structure and popular media in Pakistan that collectively reinforces the identity of state-centric nationalism. The Pakistani state is not so much a subordinate to dominant ethnic groups but works in partnership with them. This partnership is reinforced when the state is challenged by regional minority groups, itself a response generated by assimilative pressures, policies on in-migration, economic competition and more recently political threats of secession. Simply put, Pakistan's 
fragility begins with a weakness in legitimacy structures which rather than being adaptively modified in a positive way are negatively reinforced, with the consequence of increasing instability over the short run.

The feedback loop is pernicious because when Pakistan experiences internal legitimacy challenges there is an effort to reinforce oppressive authority structures, no matter how weak they are as a bulwark against further decline. Such an emphasis, exemplified in the United States' long-term aid program for Pakistan (as a result of its support for allies in the Global War on Terror), led to a potential distortion in both the selection of aid recipients, and the type of aid provided. A large amount of aid, including billions of dollars in military aid from the United States, has been given to Pakistan, regardless of the legitimacy of the regime in power. The results are deeply unpopular, and contribute to the persistence of nearly illegitimate regimes dependent on external aid, and that are unstable over the long term.

For the in and out cases, let us consider Mali and Laos. In the case of Mali, CIFP's data indicates that Mali has been in and out of the top 40 fragile states at least four times, with a deteriorating trend in the last few years after the Tuareg rebellion and military coup in 2012. The main source of Mali's fragility has to do with challenges to authority, partly as a result of lack of control over its territory and people. Conversely, recovery from fragility occurs when challenges to authority are terminated, even if only temporarily. Capacity problems resulting from a weak aid-dependent economy have kept the country close to the cut-off for exiting fragility and very vulnerable to shocks.

Mali's spectacular collapse in recent years has sparked a re-examination of its characterization as a model of stability in North Africa. In reality, Mali has never been such a model (Carment \& Samy, in press) and its recent conflict is the rule rather than the exception. The picture of Mali is of a country that continually exits fragility, only to re-enter it further down the road. This underperformance is concomitant with an increase in international development assistance. Mali has generally been an aid-dependent country, but aid increased substantially in real terms since its attempts to transition to a hybrid form of democracy in the 1990s. The effects of increasing aid, driven in part by promises to reform economically and politically, have been staggeringly negative. That is because Mali's elite benefit from aid by 'brokering' its distribution. In order to operate effectively, internationally funded NGOs rely on the cooperation (or at least benign neglect) of local government institutions (Carment \& Samy, in press). In Mali, this has resulted in political alliances between influential politicians cum aid brokers and key NGOs. Far from representing the interests of the people by establishing and adhering to institutional performance measures under a democratic system, the goal is to establish a patronage network and push for additional zones around areas over which they have more control.
More generally, Mali's aid economy offers a viable option to the thin veneer of democratic reform on display to the donor community. For example, partnering with a development NGO allows local politicians an opportunity to skim funds, either directly, or indirectly by influencing where the money is spent. Additionally, NGOs need to engage the population. In a country where the majority are illiterate, well-educated elites are hired. These elite constitute the bridge between regions and the state but operate from within the state apparatus and therefore are uncritical of it, and the legitimacy that underpins it (Carment \& Samy, in press). It becomes self-evident why democratic institutions have little purpose under such an arrangement, other than providing the cloak of international legitimacy through which state and regional elites can ensure resource distribution for the people of Mali. However, such a system has the potential to underresource key sectors of society which do not factor into the maintenance of this economic system, such as the military (Carment \& Samy, in press).

Unlike Mali, Laos (Laos People's Democratic Republic-Laos PDR) has never really been considered a model of stability. It is a country of only 6.2 million people, surrounded by larger, more powerful neighbours. Though both it and Mali have been afflicted by environmental calamity such as droughts, Laos has shown that it can recover in the face of adversity. The communist takeover in 1975 provided regime stability by bringing an end to years of civil war, but since then, Laos's leaders have been unable to bring meaningful reform and economic growth to their people. Until recently, the country's primary weaknesses were authority followed by capacity; when either deteriorate, the country moves back into fragility. Laos has been in and out of fragility five times over the last 30 years. The entries by Laos into the top 40 are consistent with the historical analysis coinciding with severe drought and border wars, conflict with Hmong insurgents, severe flooding and the Asian Financial Crisis of 1997. Laos' subsequent improvement from about 2009 onward is a result of the regime's slow but positive reforms to address security and economic stabilisation.

Economic growth has proved a double edge sword for Laos. With a number of trading partners to work with, Laotian elites have proved adept at insinuating their own economic interests into trade and investment frameworks that Laos has with established regional powerhouses. Though there are immense dependencies within these relationships, it has also meant that Laos has benefitted from a much greater political latitude that imposed structural adjustment programmes and aid programmes normally generate. In essence, Laos' improvement over the last 10 years can be understood from the perspective of spillover of economic success from its larger neighbours without the democratic baggage. But the country's weakness also emanates from the same source. There are relatively few reform-minded elites who are able to shrug off the mantle of risk averse communist style Politburo decision-making. 
The result of such a political economy is one which is entirely dependent on the ruling regime for rent redistribution. Indeed, the few sectors which have experienced liberalization have been those primarily devoted to resource extraction/export, which are dominated by party or military officials. Thus, if there is a weakness in Laos's trajectory it is simply that its leaders are slow to make policy decisions that could improve the lives of average citizens. These outputs in turn should create expectations, raise accountability and open up the political system. Instead, the regime concentrates on liberalizing and expanding only those sectors which it fully controls for fear they could lose power, influence and income.

In comparing Laos with Mali, we see there are two different paths. One (Mali) is the possibility of regression and succumbing eventually to lethal feedback loops, the other (Laos) is a potentially stable exit. The likelihood of a stable exit assumes that reformists within government eventually succeed in expanding resource distribution. Conversely, a lethal feedback loop awaits those countries with poor economic performance, coupled with an economy based on aid dependence. Under such conditions, as we have seen with the trapped states, a focus on security issues at the expense of stronger state-society relations undermines further economic growth.

We turn now to Bangladesh and Mozambique both of which have built resilience and exited fragility. In the case of Bangladesh, as one of the most fragile countries in the world in 1980, it left the top 40 ranking in 1991 and has only gone back into that category twice (in 2004-2005 and 2007-2008). According to CIFP's data, this transformation is the result of improvements in authority and legitimacy, and also a gradual improvement in capacity. A key contributing factor was the replacement of military control in domestic crisis management through opportunities for political mobilization and reform. With the help of international donors, political reform was followed by improved economic performance and improvements in authority. Even moderate commitments to reform have made a big difference. Bangladesh realized a respectable level of civilianization of its military leaders and a nascent, if not dysfunctional, multiparty political organization (Carment \& Samy, in press). The leaders of Mozambique's Frelimo showed flexibility and pragmatism in the aftermath of protracted war. Instead of focusing on revenge, they focused on economic growth. For Bangladesh, the country's strong improvement in capacity fuelled by rapid economic growth was reinforced by powerful deep-rooted patron-client relations, resilience in the face of adversity, and a strong civil society presence. Mozambique in contrast, though its economic growth is strong, is run by a rent seeking political party that appears unwilling to relinquish control.

Just as Pakistan and Yemen remain trapped because of legitimacy issues that further undermine authority structures, Bangladesh was able to create space for civil society and new political parties. The resulting legitimacy enabled export-led manufacturing to drive the economy, and allowed the country to exit from being a fragile state. Mozambique, for its part, was able to exit fragility at the end of the civil war in 1992. The largest improvements towards the end of the civil war and thereafter were recorded in legitimacy, followed by authority. And as in the case of Bangladesh, export driven economic growth helped Mozambique to exit. Both countries exited from fragility through two stages. First by overcoming the adversities of war as well as meeting the challenges of natural and man-made disasters (flooding in the case of Bangladesh, demining in the case of Mozambique) and second by focusing on economic growth through significant reforms implemented with support from the international community. During the first phase, we see decreasing volatility in both legitimacy and authority and only later in the second phase improvements in capacity based on economic growth and more diversified economies.

These transitions have been far from perfect. Both aid and extractive industry rents have aggravated Mozambique's fragility by undermining regime legitimacy and effectiveness due to poor resource distribution. Maputo's growth is not matched by equivalent gains in the hinterland. The absence of accountability is key here. For example, Perez Nino and Le Billon (2013) argue that Mozambique will ultimately fall back into fragility because of its low tax burden on elites which in turn puts minimal pressure on these elites to provide social spending for all Mozambicans.

Politically, as hybrid democracies both countries have substantial difficulties in managing political transitions without violence and political unrest. Mozambique introduced multi-party elections in 1989 though Frelimo has ruled ever since. Bangladesh is a multi-party democracy but one consistently undermined by cronyism, corruption and dynasticism. To be fair, much of Bangladesh and Mozambique's corruption might be reinvested in their respective economies creating a kind of virtuous feedback loop. But other virtuous feedback loops are present, including investments in human capital projects, to some degree gender empowerment (in the case of Bangladesh) and spontaneous forms of privatization. These all serve to indirectly improve legitimacy and authority by reducing social unrest and improving legitimacy outputs.

These two cases show that it is possible for countries to exit fragility with the right mix of political and economic reforms in the presence of independent political institutions and support from the international community. Whether both cases remain out of fragility will depend not simply on continued economic growth and capacity improvements, but on whether state-society relations remain strong. Mozambique's future is less clearcut than Bangladesh's. If there is a major constraint for Mozambique, it is its inability to match poverty reduction with rapid economic growth especially as new sectors such as mining show lower levels of productivity.

Like Bangladesh, Mozambique's political and economic interdependencies were most evident in its for- 
mative years after the war. Where catalysing negative effects had the potential to shift the country downward, political leadership moved the country in a more positive direction with the support of the international community. When stressed, as in a time of political upheaval, Mozambique's leaders revealed a modest ability to recuperate.

To summarize, the statistical analysis by Carment and Samy (2017) showed that capability, legitimacy and conflict (to a certain degree) are key correlates of the fragility trap. The capability and conflict traps are equivalent to authority according to CIFP's framework, and the legitimacy trap with CIFP's legitimacy cluster. While conflict is a factor that was present in all of the above cases at one point or another in their recent history, it was not a leading reason for how fragile they are or have been. Yemen is the only case where conflict has arguably kept it trapped. The dominance of the military in the case of Pakistan has prevented it from succumbing to a lethal feedback loop but the result is deteriorating state legitimacy and limited political freedoms. In the case of Bangladesh and Mozambique, both recovered from large scale civil conflicts as a result of political and economic processes that were both legitimate and sustainable. For the two in and out countries, Mali and Laos, low intensity conflicts have made it more difficult to assert authority and build legitimacy, especially for Mali, though less so in the case of Laos.

The inherent difficulty of a fragile state attempting to exit the trap is straightforward. Leaders of deeply fragile states are able to survive with a small but powerful support base by tying private welfare to their own welfare (Carment \& Samy, in press). Even though the state is the primary instrument of power and may even indeed possess overwhelming coercive capacity, its leaders lack the autonomy to affect concessions for reform. Since a necessary ingredient for implementing reform is public support for such policies, elites that are unaccountable to the larger population (in which the possibility of overturning the government is always present) have little incentive to pursue change. Legitimacy is weakened even further when elites are forced to expend greater resources on coercive means in order to ensure they are obeyed. Under these conditions, elites express only a minimal commitment to reform. This is because the centralization of state authority and the pursuit of development policies aimed at maximizing revenues and rents, rather than social welfare, produce a process which has non-elected institutions and elites dominating.

States remain trapped or fall back into fragility when they fail to provide public goods that benefit large parts of the population, even in the face of improved capacity. Situations where there is a decline in the provision of public goods is often followed by decreasing volun- tary compliance, such as tax payment, which can in turn reduce government effectiveness further. Given the importance of legitimacy and authority for the evolution of states, and the lack of evidence supporting the poverty trap, in the next section we examine how aid is allocated to these various countries.

\section{Sectoral Aid Allocations and the CIFP Framework}

In this section, we use gross official development assistance (or foreign aid) disbursements from all Development Assistance Committee (DAC) donors to compare aid allocation across the six country-cases discussed earlier. $^{6}$ Of the six countries, Mozambique is currently the most aid dependent country with an aid to gross national income ratio of $14 \%$ in 2016, followed by Mali (9\%) and Yemen (7\%) according to data from the World Bank's World Development Indicators dataset. On the other hand, the numbers for Bangladesh and Pakistan are around $1 \%$, and $2-3 \%$ in the case of Laos. However, even in the case of Bangladesh and Laos, aid represents a fairly significant percentage of central government expenditure (which arguably is a better measure since it shows the extent to which states rely on foreign aid for their budgets) at $12 \%$ and $18 \%$ respectively, while in the case of Mali it is an incredible $70 \%$, for 2016 . Therefore, the countries that we examine are quite dependent on foreign aid. We calculate the average sectoral aid allocation using the CRS aid activity of the OECD for the period 2003-2016 during which detailed sectoral level data is available for our six country-cases.

Of most relevance to us is aid allocated to social infrastructure and services which comprises anywhere from 41 to $51 \%$ of aid allocated (see column (a) of Table 1) and is by far the most important sector. ${ }^{7}$ This sector is relevant because it includes aid allocated towards education, health, population policies and programmes, water supply and sanitation, government and civil society, and other social infrastructure. Except for government and civil society, all the other categories are mostly related to capacity in the ALC framework. As can be seen in column (b) of Table 1, they comprise a significant proportion of column (a); for example, in the case of Pakistan, they account for $75 \%$ of aid allocated towards social infrastructure and services, while government and civil society accounts for the remaining $25 \%$. This is in fact a pattern that repeats itself across all the six country-cases, with most aid going towards capacity-related issues.

The difference between columns (a) and (b) is aid allocated to government and civil society (column (c)). The latter can be further broken down as government and civil society-general (column (d)) and conflict, peace and security (column (e)). Government and civil societygeneral, includes funding for democratic participation

\footnotetext{
${ }^{6}$ Our analysis excludes military aid because we focus on official development assistance. However, we are aware that this is significant for countries such as Pakistan. For example, for several years after the 9/11 attacks, United States security assistance to Pakistan exceeded economic assistance (see Center for Global Development, n.d.).

${ }^{7}$ Other sectors include economic infrastructure, production sectors, multi-sector/cross-cutting, commodity aid, action related to debt, humanitarian assistance, administrative costs of donors, refugees in donor countries and unallocated/unspecified.
} 
Table 1. Aid allocation to social infrastructure and services as a \% of total aid, 2003-2016. Source: OECD DAC CRS (OECD, n.d.).

\begin{tabular}{|c|c|c|c|c|c|}
\hline \multirow{2}{*}{ Country } & \multirow{2}{*}{ Total } & \multirow{2}{*}{$\begin{array}{l}\text { Education, Health, Population, Water } \\
\text { Supply, Other Social Infrastructure }\end{array}$} & \multicolumn{3}{|c|}{ Government and Civil Society } \\
\hline & & & Total & General & Conflict, Peace and Security \\
\hline & (a) & (b) & (c) & (d) & (e) \\
\hline Pakistan & 41.1 & 30.6 & 10.5 & 9.4 & 1.1 \\
\hline Yemen & 51.1 & 41.4 & 9.7 & 8.4 & 1.3 \\
\hline Mali & 47.4 & 36.4 & 11.0 & 9.3 & 1.7 \\
\hline Laos & 43.6 & 31.6 & 12.0 & 7.4 & 4.6 \\
\hline Bangladesh & 41.3 & 33.4 & 7.9 & 7.7 & 0.1 \\
\hline Mozambique & 50.9 & 42.2 & 8.7 & 8.0 & 0.7 \\
\hline
\end{tabular}

and civil society, elections and human rights. $^{8}$ These are related to legitimacy under the ALC framework and represent between $7.4 \%$ to $9.4 \%$ on average (column (d)). Aid allocated towards conflict, peace and security (column (e))-which under the ALC framework fits under authority-is even smaller, accounting for less than $2 \%$ for most of the country-cases. Part of the explanation for why most aid goes to capacity and less to authority and legitimacy may have to do with the short time horizon of donors that are often in search of quick wins. Indeed, it is easier to see results when one builds a school or invests in healthcare but, for example, political stability (building authority) and improving the quality of democracy (building legitimacy) are more difficult to achieve even if long-term impacts may be far more important in helping states become resilient.

Two trends are clear from the above analysis. First, a very high proportion of aid is allocated towards capacity but less so towards legitimacy and authority. We are not arguing that capacity is not important. Issues such as education and health, which have been prioritized by donors, and especially after the adoption of the Millennium Development Goals, attracted a lot of funding in the years that followed. On the other hand, to the extent that authority and legitimacy matter for the evolution of states, particularly those that are trapped or are falling back into the trap, they are, comparatively, areas that have not received the same level of attention. We should note that even if we report averages in Table 1, examining variation over time does not change our overall conclusions. Furthermore, in countries such as Pakistan, if we think beyond development aid to consider other forms of assistance, large amounts of aid from the United States, including significant military assistance, have undermined rather than promote democracy (Ali, 2009).

While the low percentages allocated towards "conflict, peace and security" make sense in the case of Bangladesh and Mozambique, our two exit states, the same cannot be said about Mali or Yemen. We should note that the results reported here differ from those in
Carment et al. (2008), in part because the current article focuses on a narrow set of countries, whereas the former examines aid allocation for all countries that include both fragile and non-fragile countries. However, they still confirm that legitimacy is not a factor that seems to be taken into account by donors. Second, the sectoral allocation of aid towards legitimacy (see column (d)) does not seem to vary much across the six country-cases, even if the situation of these countries with respect to fragility and its evolution is quite different.

\section{Conclusions}

While issues of aid allocation and aid effectiveness have received a lot of attention in the academic and policy literature, comparatively less has been written about these issues with respect to fragile states. Of the few papers that have done so and discussed at the beginning of this article, none have, as far as we are aware, combined the findings of quantitative analysis with specific countrycases to examine whether aid is targeted towards the characteristics that explain the evolution of states. This is what we set out to do in this article. By comparing the sectoral allocation of aid with the CIFP framework, we have shown that aid allocation does not pay sufficient attention to issues of legitimacy and authority that are both important for understanding why countries are fragile. While measuring aid effectiveness (i.e. the impact of aid) is beyond the scope of the current article, we think that a first step is making sure that aid is targeted where it is needed. And for this, it is paramount that donors pay more attention to the multiple ways in which countries are fragile, and the conditions that prevent them from exiting fragility permanently such as lethal and pernicous feedback loops, rent seeking and failure to buy reform.

In this context, for those states where fragility is persistent we find that elites who are resistant to change engage in damaging and self-interested behaviour such as corruption and rent seeking. With a focus on symptoms rather than causes, policies are rarely successful

\footnotetext{
${ }^{8}$ This includes funding towards public management and domestic revenue mobilization, which can help countries build authority through taxation. As pointed out by Tilly (1975) and Herbst (2000), taxation is fundamental for statebuilding and creates a fiscal pact between citizens and the state. Unfortunately, as noted by Culpeper and Bhushan (2010), for example, a very small fraction of technical assistance is devoted to public sector financial management in sub-Saharan Africa.
} 
because they do not get to the core of the fragility trap problem. International and domestic incentives for leaders of trapped states to embrace reforms that affect their personal interests are often too weak. Indeed, policies intended to induce reform are not only misplaced, they are often counterproductive (Chauvet \& Collier, 2008). In addition to the dilemma that selectivity poses for fragile states (see introduction), there is an extensive literature on conditionality associated with aid programs reinforcing our point that aid conditionality fails more often than not (see, for example, Collier, 1997, and Dijkstra, 2002). That is because they rely on causal explanations focusing on one structural factor such as economic development or political development, which by themselves are insufficient. In many of these interpretations, fragility is usually associated with poor policy environments, aid absorption problems, conflict and poverty.

We find that policies focused purely on structure will be misplaced if there is limited willingness for leaders of trapped states to reform. We emphasize the importance of state-society relations, specifically the role of legitimacy in underpinning the behaviour of political, social and economic elites, in the formation of undergoverned spaces and a coercive state apparatus, rent seeking behaviour, and in building a less resilient society overall. These assumptions are premised on claims regarding interactions between the superordinate elements of state authority, capacity, and legitimacy and not just economic development and democracy. For a state that has exited fragility, positive changes in authority that address societal well-being not only provide valuable guidance for government policy, they also reduce literal barriers to commerce and economic development (measures of capacity) such as restrictions on citizen movement and assembly (measures of legitimacy). Responsiveness also induces governments to produce policies addressing popular concerns that are not growth-focused, such as wealth distribution and social programming, and which by extension increase state legitimacy.

Our overall conclusion is that trapped states are most prone to lethal and pernicious feedback loops. In general terms, strengthening authority structures without appropriate resource distribution goes hand in hand with declining legitimacy. Capacity is skewed to maintaining control over the distribution of resources and rents in favour of entrenched and often, unelected elites. Fissures based on ethnic cleavages, elite capture and rent seeking behaviour are met with coercive measures to maintain stability but come at the costs of further declines in legitimacy. Lethal feedback loops occur when regime survival is tied to a declining rent economy leading to reduced capacity and control over territory and ultimately collapse. Undergoverned spaces increase over time, as patronclient politics and resources weaken simultaneously. Under these conditions, elites express only a minimal commitment to reform. This is because the centralization of state authority and the pursuit of development policies aimed at maximizing revenues and rents, rather than so- cial welfare, produce a process which has non-elected institutions and elites dominating. There is only a limited opportunity for elites to pursue reforms.

\section{Acknowledgments}

We would like to thank Carleton University and the Social Sciences and Humanities Research Council of Canada for supporting this research, and in particular, for allowing us to continue to maintain the CIFP database on fragile states.

\section{Conflict of Interests}

The authors declare no conflict of interests.

\section{References}

Ali, M. (2009). US aid to Pakistan and democracy. Policy Perspectives, 6(2), 119-132.

Andrimihaja, N. A., Cinyabuguma, M. M., \& Devarajan, S. (2011). Avoiding the fragility trap in Africa (World Bank Policy Research Working Paper Series). Washington, DC: World Bank.

Burnside, C., \& Dollar, D. (2000). Aid, policies and growth. The American Economic Review, 90(4), 847-868.

Call, C. T. (2011). Beyond the failed state: Toward conceptual alternatives. European Journal of International Relations, 17(2), 303-326.

Carment, D., \& Samy, Y. (in press). Exiting the fragility trap: Rethinking our approach to the world's most fragile states. Athens, $\mathrm{OH}$ : Ohio University Press.

Carment, D., \& Samy, Y. (2017). Exiting the fragility trap: Rethinking our approach to the world's most fragile states (UNU-WIDER Working Paper 2017/181). Helsinki: UNU-WIDER.

Carment, D., Prest, S., \& Samy, Y. (2008). State fragility and implications for aid allocation: An empirical analysis. Conflict Management and Peace Science, 25(4), 349-373.

Carment, D., Prest, S., \& Samy, Y. (2009). Security, development and the fragile state: Bridging the gap between theory and policy. Abingdon: Routledge.

Center for Global Development. (n.d.). Aid to Pakistan by the numbers. Center for Global Development. Retrieved from https://www.cgdev.org/page/ aid-pakistan-numbers

Chauvet, L., \& Collier, P. (2008). What are the preconditions for turnarounds in failing states? Conflict Management and Peace Science, 25(4), 335-348.

Clark, V. (2010). Yemen: Dancing on the heads of snakes. New Haven, CT: Yale University Press.

Collier, P. (1997). The failure of conditionality. In C. Gwin \& J. Nelson (Eds.), Perspectives on aid and development. Washington, DC: Overseas Development Council.

Country Indicators for Foreign Policy. (n.d.). Country Indicators for Foreign Policy. Retrieved from https:// 
carleton.ca/cifp

Culpeper, R., \& Bhushan, A. (2010). Why enhance domestic resource mobilisation in Africa? Trade Negotiations Insight, 9(6). Retrieved from https:// www.ictsd.org/bridges-news/trade-negotiationsinsights/news/why-enhance-domestic-resourcemobilisation-in-africa

Dijkstra, G. A. (2002). The effectiveness of policy conditionality: Eight country experiences. Development and Change, 33(2), 307-334.

Gravingholt, J., Ziaja, S., \& Kreibaum, M. (2015). Disaggregating state fragility: A method to establish a multidimensional empirical typology. Third World Quarterly, 36(7), 1281-1298.

Hansen, H., \& Tarp, F. (2000). Aid effectiveness disputed. Journal of International Development, 12(3), 375-398.

Herbst, J. (2000). States and power in Africa: Comparative lessons in authority and control. Princeton, NJ: Princeton University Press.

McGillivray, M. (2006). Aid allocation and fragile states (UNU-WIDER Working Paper No. 2006/01). Helsinki: UNU-WIDER.

McGillivray, M., \& Feeny, S. (2008). Aid and growth in fragile states (UNU-WIDER Working Paper No. 2008/03). Helsinki: UNU-WIDER.

Messner, J. J. (2018). Fragile states index 2018: Issues of fragility touch the world's richest and most developed countries in 2018. Fund for Peace. Retrieved from https://fundforpeace.org/2018/04/19/fragilestates-index-2018-issues-of-fragility-touch-theworlds-richest-and-most-developed-countries-in2018
OECD. (n.d.). OECD Statistics. Retrieved from https:// stats.oecd.org/Index.aspx?DataSetCode=CRS1

OECD. (2015). States of fragility 2015: Meeting post-2015 ambitions. Paris: OECD Publishing.

OECD. (2018). States of fragility 2018. Paris: OECD Publishing.

Perez Nino, H., \& Le Billon, P. (2013). Foreign aid, resource rents and institution building in Mozambique and Angola (UNU-WIDER Working Paper No. 2013/102). Helsinki: UNU-WIDER.

Pritchett, L., \& de Weijer, F. (2010). Fragile states: Stuck in a capability trap? (World Development Report 2011 Background Paper, November 5). Washington, DC: World Bank.

Pritchett, L., Woolcock, M., \& Andrews, M. (2010). Capability traps? The mechanisms of persistent implementation failure (Center for Global Development Working Paper 234). Washington, DC: Center for Global Development.

Save the Children. (2018). Yemen: 85,000 children may have died from starvation since start of war. Save the Children. Retrieved from https://www. savethechildren.net/article/yemen-85000-childrenmay-have-died-starvation-start-war

Takeuchi, S., Murotani, R., \& Tsunekawa, K. (2011). Capacity traps and legitimacy traps: Development assistance and state building in fragile situations. In $\mathrm{H}$. Kharas, K. Makino, \& W. Jung (Eds.), Catalyzing development: A new vision for aid. Washington, DC: Brookings Institute Press.

Tilly, C. (1975). The formation of national states in Western Europe. Princeton, NJ: Princeton University Press.

\section{About the Authors}
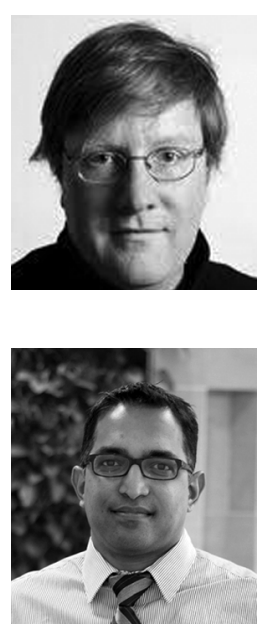

David Carment is Series Editor for Palgrave's Canada and International Affairs, Editor of Canadian Foreign Policy Journal and Fellow of the Canadian Global Affairs Institute. His research focuses on Canadian foreign policy, fragile states and diaspora politics. He is the author, editor or co-editor of 16 books and has authored or co-authored over 70 peer reviewed journal articles and book chapters. His most recent books focus on diaspora cooperation in Canada, Canadian foreign policy and state fragility.

Yiagadeesen Samy is a Professor of International Affairs and the Director at the Norman Paterson School of International Affairs, Carleton University, Ottawa, Canada. He has published widely on issues related to international economics and economic development. His current research interests include fragile states and state transitions, aid effectiveness, domestic resource mobilization and income inequality. His book African Economic Development (with Archibald Ritter and Steven Langdon) was published by Routledge in 2018. 